\title{
Exploring retailers' sensitivity to local sustainability policies
}

\author{
H.J. Quak and M.B.M. de Koster
}

\begin{tabular}{|l|l|}
\hline \multicolumn{2}{|l|}{ ERIM REPORT SERIES RESEARCH IN MANAGEMENT } \\
\hline ERIM Report Series reference number & ERS-2005-066-LIS \\
\hline Publication & November 2005 \\
\hline Number of pages & 24 \\
\hline Persistent paper URL & \\
\hline Email address corresponding author & hquak@rsm.nl \\
\hline Address & Erasmus Research Institute of Management (ERIM) \\
& RSM Erasmus University / Erasmus School of Economics \\
& Erasmus Universiteit Rotterdam \\
& P.O.Box 1738 \\
& 3000 DR Rotterdam, The Netherlands \\
& Phone: $\quad+31104081182$ \\
& Fax: $\quad+31104089640$ \\
& Email: info@erim.eur.nl \\
& Internet: $\quad$ www.erim.eur.nl \\
\hline
\end{tabular}

Bibliographic data and classifications of all the ERIM reports are also available on the ERIM website: www.erim.eur.nl 


\section{ERASMUS RESEARCH INSTITUTE OF MANAGEMENT}

\section{REPORT SERIES}

\section{RESEARCH IN MANAGEMENT}

\begin{tabular}{|c|c|}
\hline \multicolumn{2}{|c|}{ ABSTRACT AND KEYWORDS } \\
\hline Abstract & $\begin{array}{l}\text { Local governments in Western Europe increasingly use city time-access regulations to improve } \\
\text { social sustainability. These regulations significantly influence the distribution process of retail } \\
\text { chain organizations. This paper studies the impact of governmental timewindow pressure on } \\
\text { retailers' logistical concept and consequential financial and environmental distribution } \\
\text { performance. We determine which dimensions in the retailer's logistical concept determine its } \\
\text { cost and emission sensitivity to increasing time-window pressure. Our research is based on a } \\
\text { multiple case study of fourteen Dutch retail cases in different sectors and with different store } \\
\text { formulas. The retailers provided all organizational, flow and cost data of their secondary } \\
\text { distribution (between distribution center and stores). We use these data to calculate the impacts } \\
\text { of different time-window pressure scenarios, including the current situation, using vehicle routing } \\
\text { software. It appears that cost increases are moderate, when few cities are affected. However, as } \\
\text { more cities are affected, costs increase considerably, particularly if time-window lengths become } \\
\text { shorter. Time-windows harmonized between cities, lead to less negative effects. We find various } \\
\text { dimensions that contribute to reducing the retailer's sensitivity to timewindow pressure. We } \\
\text { formulate conclusions hypothesizing the links between timewindow pressure, its effects, and the } \\
\text { dimensions that determine these effects. }\end{array}$ \\
\hline Free Keywords & Sustainability, Governmental Regulation, City Logistics / Distribution, Retail, Case Study \\
\hline Availability & $\begin{array}{l}\text { The ERIM Report Series is distributed through the following platforms: } \\
\text { Academic Repository at Erasmus University (DEAR), DEAR ERIM Series Portal } \\
\text { Social Science Research Network (SSRN), SSRN ERIM Series Webpage } \\
\text { Research Papers in Economics (REPEC), REPEC ERIM Series Webpage }\end{array}$ \\
\hline Classifications & $\begin{array}{l}\text { The electronic versions of the papers in the ERIM report Series contain bibliographic metadata } \\
\text { by the following classification systems: } \\
\text { Library of Congress Classification, (LCC) LCC Webpage } \\
\text { Journal of Economic Literature, (JEL), JEL Webpage } \\
\text { ACM Computing Classification System CCS Webpage } \\
\text { Inspec Classification scheme (ICS), ICS Webpage }\end{array}$ \\
\hline
\end{tabular}




\section{Exploring retailers' sensitivity to local sustainability policies}

\section{H.J. Quak and M.B.M. de Koster}

H.J. Quak

Address: Room T10-50, PO Box 1738

3000DR Rotterdam

The Netherlands

Tel. +31104081869

Fax. +31104089014

E-mail: hquak@rsm.nl
M.B.M. de Koster

Address: Room T10-56, PO Box 1738

3000DR Rotterdam

The Netherlands

Tel. +31104081992

Fax. +31104089014

E-mail: rkoster@rsm.nl 


\title{
Exploring retailers' sensitivity to local sustainability policies
}

\begin{abstract}
Local governments in Western Europe increasingly use city time-access regulations to improve social sustainability. These regulations significantly influence the distribution process of retail chain organizations. This paper studies the impact of governmental timewindow pressure on retailers' logistical concept and consequential financial and environmental distribution performance. We determine which dimensions in the retailer's logistical concept determine its cost and emission sensitivity to increasing time-window pressure. Our research is based on a multiple case study of fourteen Dutch retail cases in different sectors and with different store formulas. The retailers provided all organizational, flow and cost data of their secondary distribution (between distribution center and stores). We use these data to calculate the impacts of different time-window pressure scenarios, including the current situation, using vehicle routing software. It appears that cost increases are moderate, when few cities are affected. However, as more cities are affected, costs increase considerably, particularly if time-window lengths become shorter. Time-windows harmonized between cities, lead to less negative effects. We find various dimensions that contribute to reducing the retailer's sensitivity to timewindow pressure. We formulate conclusions hypothesizing the links between timewindow pressure, its effects, and the dimensions that determine these effects.
\end{abstract}

\section{Keywords}

sustainability, governmental regulation, city logistics / distribution, retail, case study

\section{Introduction}

Marshall and Toffel (2005) structure sustainability-issues in a four-level hierarchy, in which the successive levels refer to increasingly higher order sustainability needs (Figure 1). Transport is recognized to be one of the most significant sources of unsustainability in urban areas (May et al., 2003), impacting multiple levels of Marshall and Toffel's hierarchy. It is responsible for fossil fuel use, global pollutant emissions responsible for global warming, consequences of emissions on public health, and injuries and deaths resulting from traffic accidents (Browne and Allen, 1999). Furthermore, it is responsible for noise, congestion and decreased city accessibility, visual intrusion, vibration (Browne and Allen, 1999), loss of greenfield sites and open space, and damage of infrastructure and (historical) buildings from heavy vehicles (Banister et al., 2000). In spite of all these unsustainable impacts, urban freight transport is fundamental to the economic vitality and competitiveness of industrial, trade and leisure activities that are essential to wealth generation (Anderson et al., 2005; Ogden, 1992). Rapid and reliable goods distribution supports urban lifestyles and is an important element of the urban economy (Browne and Allen, 1999).

The increasing negative effects of transport have attracted the interest of policymaking bodies (see e.g. CEC, 2001a, 2001b; DETR, 1998, 1999; and EAA, 2001) as well as of researchers (see e.g. Crainica et al., 2004; Regan and Golob, 2005). Several authors (e.g. Feitelson, 2002; Nicolas et al., 2003; and Richardson, 2005) distinguish three sustainability issues: environmental sustainability, economic sustainability, and social 
sustainability, also known as the triple-bottom-line or triple-P: people, profit, and planet. A popular policy measure to improve the social sustainability in urban areas, especially in Europe, is the use of time-access restrictions (OECD, 2003). A time-access restriction, or time-window, forces the distribution activities to take place within a specified period of the day. The objective of time-windows is to reduce the perceived impacts caused by large vehicles in shopping centers, such as visual intrusion, intimidation, safety infringement, vibration and noise (Allen et al., 2004), and to separate the freight carriers from the shopping public using cars to visit the shopping areas (Munuzuri et al., 2005).

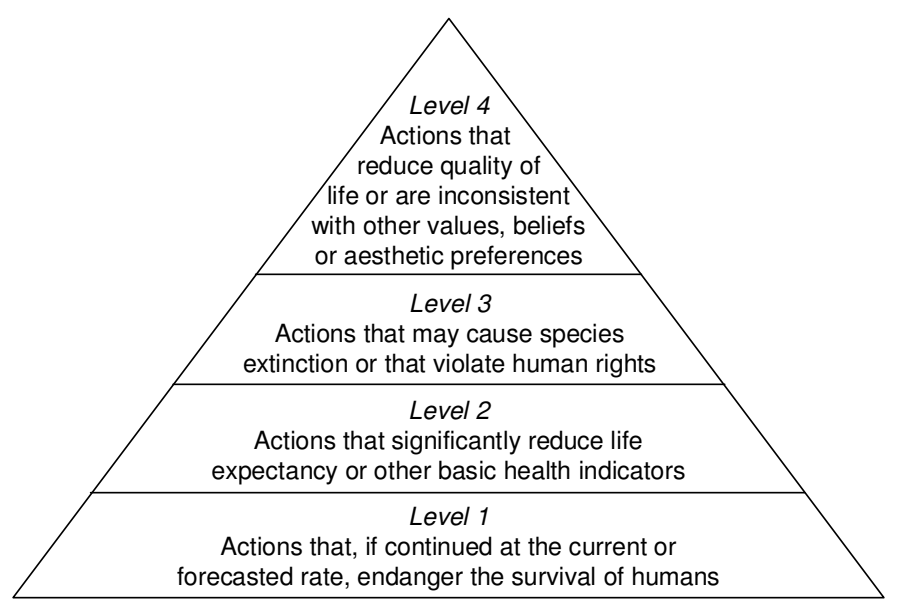

Figure 1 Unsustainability hierarchy of Marshall and Toffel (2005)

Apparently time-window restrictions (and other vehicle restrictions) are effective, as the OECD (2003) report shows that they gain in popularity in many, especially Western European, countries. In the Netherlands for example, only $41 \%$ of the municipalities used time-windows in 1998; this increased to 53\% in 2002. Particularly the larger municipalities use time-windows: $71 \%$ of the top 100 largest municipalities and all top 20 municipalities in the Netherlands use them. Simultaneously, the average time-window length decreases (PSD, 2002). Many forwarders consider time-windows to be one of their most urgent problems in distributing goods in urban areas (Crum and Vossen, 2000). Groothedde and Uil (2004) estimate that time-windows increase yearly cost for Dutch retailers by about 270 million euros. As local authorities have substantial autonomy, time-window restrictions differ per municipality and are not harmonized. Carriers operate in several cities and are therefore confronted with a wide range of local restrictions (Munuzuri et al., 2005). The Dutch Minister of Transport decided, in line with the policy framework of the OECD (2003), to explore the possibilities of a more centrally governed time-window policy (Lemstra, 2004).

In spite of the wide use of time-windows, little is known on the impact of timewindow pressure on retailers' distribution costs and their environmental consequences (Anderson et al., 2005). Also, little is known about which dimensions within their logistics organization cause retailers to be more sensitive to governmental time-window pressure. In this paper we address these questions, using a multiple (14 in total) casestudy approach. Although all cases are Dutch, we deem the results to be valid for the entire Western European context. As mentioned before, time-windows are not a Dutch 
phenomenon only, but are widely used in especially Western Europe. Furthermore, the Dutch context is representative to the Western European context: all retailers use trucks as major transport mode to supply their stores and most of the store supply comes from retail warehouses. Furthermore, the costs structure, consisting of, for example, driver's wages, vehicle maintenance costs, and fuel costs, is also comparable in Western European countries. Some of the retailers involved in this study actually operate in multiple European countries and indicated to us they see no serious differences in their distribution and logistics operations between these countries.

Case research lends itself to exploratory investigations and is especially useful to answer questions of why, what and how with full understanding of the phenomenon (Meredith, 1998). Case study research consents to researchers to study a phenomenon in its natural setting. It allows researchers to generate meaningful theory from the empirical observed practice (Voss et al., 2002). This study is explorative in nature, as we explore retailers' operations reactions and cost sensitivity to time-window pressure and determine the dimensions that drive the retailer's time-window pressure sensitivity. We follow the case research steps as proposed by Voss et al. (2002).

We use scenario analysis, employing vehicle routing software to calculate (near) optimal retailer delivery routes, to assess the impact of Time-window pressure on the dependent constructs operational, financial, and environmental distribution performance. By grouping the cases per dimension of the independent constructs network structure and logistical planning, we show which dimensions are particularly responsible for a retailer's performance sensitivity to Time-window pressure. This research specifically aims to answer the following two research questions:

1. What are the impacts of time-access windows on a retailer's financial and environmental performance?

2. Which dimensions related to a retailer's logistical concept determine its performance sensitivity to time-windows?

The first research question focuses on the exact effects of changes in Time-window pressure on Distribution performance. Previous research (e.g. Allen et al., 2003; Groothedde and Uil, 2004) show that time-window restrictions cause an increase in distribution costs. However, how exactly this effect changes in case the time-window pressure varies is still an unknown area. There is no prior research studying the second research question.

In order to carefully measure the impact of Time-window pressure on the retailers' Distribution performance, the choice of unit of analysis should reflect a retail organization's distribution process to the stores. The large majority of product flows to the stores are supplied via the retailers' distribution centers (De Koster and Neuteboom, 2001). We therefore select the retailer's physical distribution process during one representative week between one distribution center and the stores that are supplied from that center as our unit of analysis, or case definition (Voss et al., 2002).

\section{Theoretical foundation and construct development}

2.1 Conceptual framework

Many textbooks use schemes that show the relations between competitive strategy, distribution networks, and distribution performance. However, only little literature uses 
constructs that measure distribution organization and performance (financial and environmental). Validated constructs available from literature (as reviewed by Chen and Paulraj, 2004; Keller et al., 2002) can therefore not be used in this study. We therefore have to define our own measurements for the constructs used. Our framework is based on the conceptual framework of Van Goor et al. (2003) (see Figure 2).

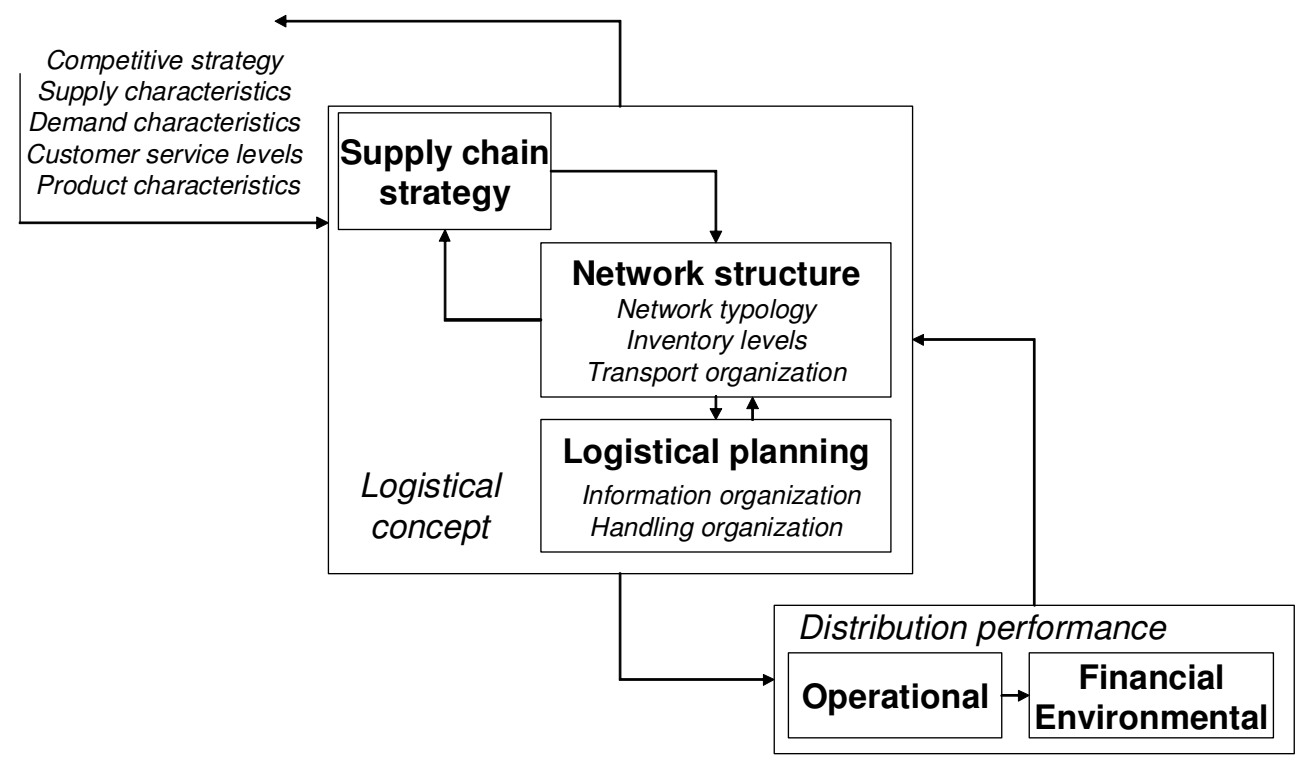

Figure 2 Conceptual framework, based on Van Goor et al. (2003)

Figure 2 shows that distribution performance is determined by the logistical concept, which is influenced by external factors: competitive strategy, supply and demand characteristics, customer services levels, and product characteristics. Heizer and Render (1999) distinguish three basic competitive strategies: competing on differentiation (e.g. Benetton), competing on costs (e.g. Wal-Mart), and competing on response (e.g. Zara). Retailers deal with their supply and demand characteristics in their supply chain strategy (Fisher, 1997; Lee, 2002). Lalonde and Zinszer (1976) show how customer service can be measured, with pretransaction, transaction, and post-transaction elements. Choices in these elements partly determine the Logistical concept (Ballou, 1992; Stock and Lambert, 2001). The product characteristics, the last external factor, differ in their product volume and value (Van Goor et al., 2003). Product characteristics can differ also in complexity. A retailer's assortment can be simple (containing products that are nonperishable, nonfragile, or no special handling is required in storage or transportation) or complex (De Koster, 2003). Product characteristics have an immediate effect on the possibilities a retailer has to design its Logistical concept.

In the conceptual framework (Figure 2), the supply chain strategy, the network structure, and the logistical planning determine the logistical concept. The supply chain strategy has to find a balance between responsiveness and efficiency (Chopra and Meindl, 2004). The supply chain strategy is either efficient, responsive, or a mix of these two (Chopra and Meindl, 2004; Fisher, 1997; Randall et al., 2003).

The network structure contains three main sub constructs: the network typology, the inventory levels, and the transport organization (Ballou, 1992; Chopra and Meindl, 2004; 
Van Goor et al., 2003). The network typology reflects a retailer's facility decisions, i.e. the number and locations of the facilities (Chopra and Meindl, 2004). The inventory levels in the stores are primarily determined by the delivery frequency and the quantity per delivery, the drop size (Stock and Lambert, 2001; Waller, 1995). The inventory levels strongly influence transport organization: transportation economies are possible due to large volume shipments (in full-truck-loads, FTL), but then larger quantities of inventory have to be stored in the distribution center or in the stores, which leads to higher inventory costs (Stock and Lambert, 2001).

Van Goor et al. (2003) distinguish Information organization and Handling organization, as main variables determining the construct Logistical planning. A strong interaction exists with Network structure. For example, if distances between distribution centers and stores become larger, transport costs increase and replenishment quantities will increase. For retail chain organizations in Western Europe, Information technology is not a main discriminator from competitors. Even hard-discounters like Aldi have moved to point-of-sale information systems and barcode technologies in the stores (Dawson, 2005). Controlling replenishment flows to the stores is also not a main distinction, as nearly all retailers use a mix of push and pull control (Chopra and Meindl, 2004). New assortments and promotional products are often pushed (divided over the stores using a central mechanism), whereas the normal assortment is usually pulled by store sales.

Retailers' experiences in Distribution performance can lead to modifications in the Logistical concept (Chopra and Meindl, 2004) and on the long-term it even can lead to changes in the competitive strategy (Stock and Lambert, 2001), see the conceptual framework (Figure 2).

Most activities (particularly warehousing and transport) in the Logistical concept can be outsourced (De Koster, 2002; Van Goor 2003). In general, retailers keep full process control and develop at most an arm's length relationship with logistical service providers. Even if transport to the stores is outsourced, the shipments are not combined with shipments of others, as the trucks are fully loaded when they leave the distribution center.

\subsection{Research framework}

Van Goor et al.'s (2003) framework is too extensive for our purpose: as our unit of analysis is limited to retailers' store distribution only, we do not use all (sub)constructs of the framework. In our research framework (see Figure 3) we operationalize the constructs of Van Goor et al.'s (2003) conceptual framework (Figure 2). The research framework includes the constructs and their measured dimensions. The feedback from the distribution performance to Logistical concept is only considered on a long-term horizon. Since this study focuses on a shorter term these feedback arrows are not included in the research framework.

\section{Network structure}

Since our cases are defined as all deliveries from one distribution center, only location decisions differ between cases. We therefore propose to measure network typology by two dimensions:

- distance between distribution center and stores (measured by the average distance between the retailer's stores and the considered retailer's distribution center) and

- percentage of stores located in shopping areas. 
Local time-window restrictions normally only apply to stores located in shopping areas. Addresses and zip-codes of shopping areas were obtained from Groothedde and Uil (2004). All retailers use trucks as only transport mode. We therefore measure the Transport organization by:

- vehicle capacity. In order to measure vehicle capacity, we follow McKinnon (2003), who distinguishes six different vehicle types, sorted on increasing load capacity:

1. small rigid ( 2 axles and under 7.5 tonnes)

2. medium rigid ( 2 axles and between 7.5 and 18 tonnes)

3. large rigid ( 2 axles and over 18 tonnes)

4. city semi-trailer ( 3 axles)

5. articulated vehicle (at least 4 axles)

6. drawbar combination

Many retailers use different vehicle types. If $n_{i}$ is the number of vehicles of type $i$, vehicle capacity is measured by $\frac{\sum_{i} i \times n_{i}}{\sum_{i} n_{i}}$.

From the case definition follows that we consider only two inventory location type per case; the retailer's distribution center and the retailer's stores. Therefore we propose to measure inventory levels by two dimensions:

- delivery frequency (measured by the average number of deliveries per store per week) and

- drop size. This dimension is measured as the fraction of vehicle capacity used for an average drop. This implies that the drop size partly depends on the vehicle capacity. FTL (full truck load)-deliveries are characterized by a drop size of one, as LTL (less than truckloads) are characterized by a value lower than one.

These last two dimensions simultaneously measure Transport organization.

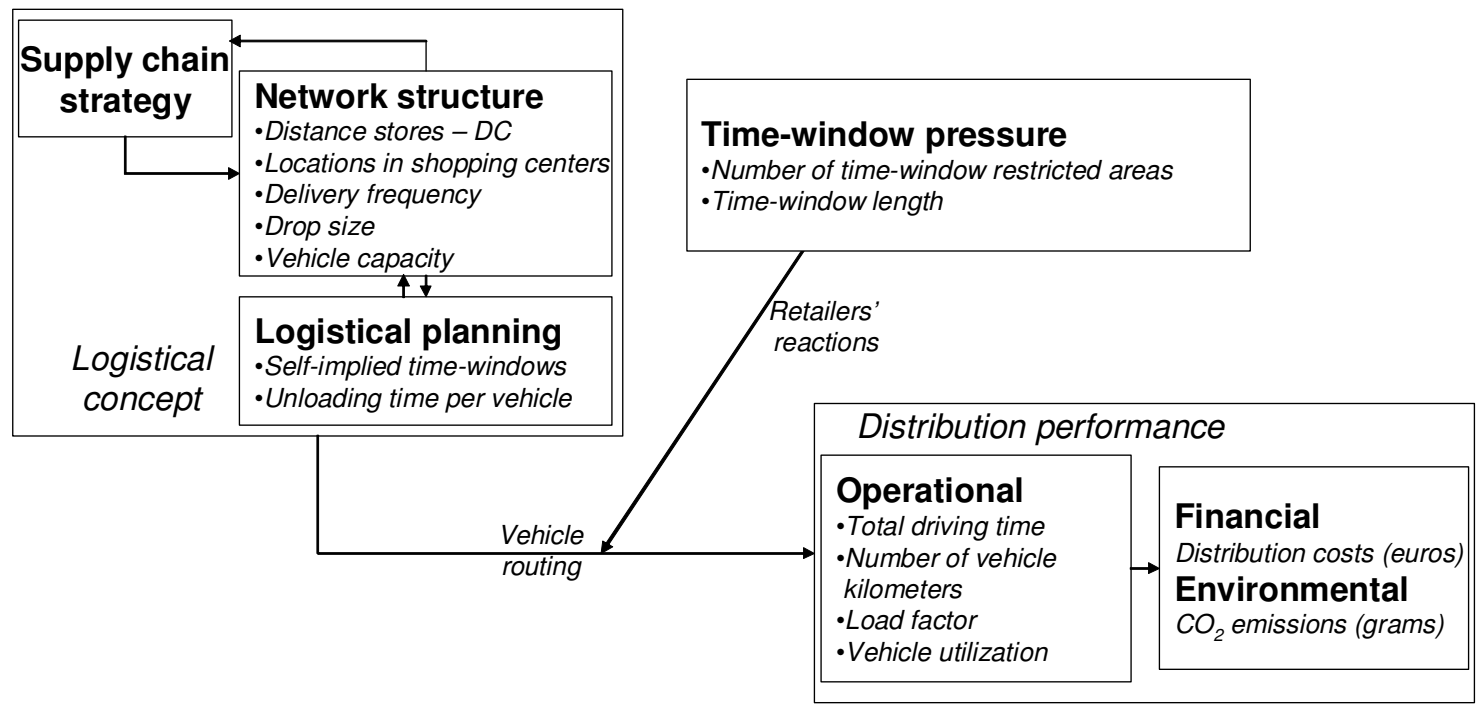

Figure 3 Research framework: Constructs and their dimensions 


\section{Logistical planning}

Handling organization is an important part of the logistical planning (Chopra, 2003). In our definition of the unit of analysis handling activities are limited to truck (un)loading at the retailers stores. Munuzuri et al. (2005) argue that the time it takes to make a delivery might influence the effect that urban freight regulations have on retailers. Therefore, we include the dimension:

- unloading time per vehicle. This dimension is the average time (in minutes) used per vehicle to load and unload at the stores during a roundtrip. It mainly depends on stop time per stop and other factors, for example whether returns have to be collected, the vehicle capacity (long vehicles take more parking time) and also on the drop size, as well as the distribution materials retailers use. For example, one retailer in this study uses a detachable swap body (a special type large rigid) that can be left at the store. This implies no combined trips and short loading and unloading times at stores and distribution center (De Koster and Neuteboom, 2001; Geerards and De Vrij, 1999). The unloading time is largely determined by the drop size, but also by a fixed time per stop, in which a driver parks the car and reports that he arrived.

To plan the loading and unloading at the stores, for example to make sure extra staff is available some retailers use self-implied time-windows. Other retailers supply their stores when there is no staff available at all; during the night. In order to deliver during the night, truck drivers possess a key to a store's depot. The higher drivers' wages for working during the night usually cause a cost increase in comparison with day deliveries (Anderson et al., 2005). We measure the planned (un)loading time at the stores by:

- self-implied time-windows. This dimension measures the of the day that supplying vehicles have to be handled at the stores. This dimension is measured by a three point ordinal scale: Narrow, medium, and wide. Narrow self-implied time-windows limit the store distribution to a smaller period of the day than the normal store's opening hours. Medium self-implied time-windows allow deliveries to take place only during the period staff is present in the stores. Wide self-implied time-windows allow the retailer to deliver also outside the hours staff is present, for example during (parts of) the nights.

\section{Distribution performance}

Urban freight transport's negative social impacts will diminish outside the time-window hours. During the time-window hours negative impacts still occur, albeit felt by fewer people. The Distribution performance shows at what consequences this improvement occurs. Allen et al. (2003) distinguish three sub constructs to reflect a company's distribution performance: operational, financial, and environmental. Taniguchi and Van Der Heijden (2000) use two constructs to evaluate the distribution performance: the financial consequences and the environmental burden.

McKinnon et al. (2003) distinguish five categories of key performance indicators that Allen et al. (2003) adapt to urban distribution operations after implementing a policy measure. Based on these indicators we use the following dimensions to describe and measure operational performance:

- total driving time. This dimension is defined as the sum of all vehicles' driving time on the road (either driving or waiting in congested areas). 
- number of vehicle kilometers. This dimension is the sum of all vehicle kilometers used to supply all stores.

- vehicle utilization. This is the average percentage of a 24-hours day that the vehicles are used for distribution activities and are not idle at the distribution center.

- vehicle load factor. The load factor is defined as the average ratio of product carriers (pallets, roll containers) to capacity when the vehicle leaves the distribution center.

These dimensions are also closely related to social sustainability indicators. For example, the number of vehicle kilometers and total driving time also indicate the impact on visual intrusion and safety (Allen et al., 2003).

Financial distribution performance is measured by the weekly distribution costs. These follow from the weekly number of vehicle kilometers, the total time used (including the (un)loading times as well as driving and waiting time), the number and types of vehicles used, and the number of roundtrips that were made. Variable costs are indicated in Table 1 and are based on the tariffs of one of the logistics service providers in this study, using the vehicles 10 hours a day. We validated these costs with all retailers, and adapted them slightly in case the retailers felt this would give a better image of the actual costs. If a vehicle is used for fewer hours than a normal day (10 hours), the hourly tariff is slightly higher. It is lower if the vehicle is used for a longer period. The logistics service provider's tariff is based on costs per hour (vehicle and driver) and costs per kilometer, and are afterwards adjusted to the time the vehicle is used per day. The costs for overtime are $€ 10$ higher per hour than in the normal situation.

Table 1 Variable costs per vehicle type

\begin{tabular}{rrrrr} 
Vehicle type & type 1-3 & type 4 & type 5 & type 6 \\
\hline Variable costs per hour & & & & \\
Vehicle & $€ 10.00$ & $€ 13.00$ & $€ 14.00$ & $€ 15.00$ \\
Driver & $€ 21.00$ & $€ 21.00$ & $€ 21.00$ & $€ 21.00$ \\
& & & & \\
Variable costs per kilometer & $€ 0.24$ & $€ 0.29$ & $€ 0.31$ & $€ 0.33$
\end{tabular}

The environmental performance is expressed in the weekly quantity of pollutant $\mathrm{CO}_{2}$ emissions (Taniguchi and Van Der Heijden, 2000). Carbon dioxide influences climate change and is responsible for global warming (Hill, 2001). Transport is responsible for over $25 \%$ of all $\mathrm{CO}_{2}$ emissions (Banister, 2000) and the amount of transport related $\mathrm{CO}_{2}$ emissions shows an increasing trend over the last years (Himanen et al., 2004). Based on the vehicle's average speed during a roundtrip, the average vehicle weight during a roundtrip, the type of vehicle (articulated or rigid), the engine type (EURO I-IV), and the number of vehicle kilometers we calculated the $\mathrm{CO}_{2}$ emissions using emission tables of NERA (2000), for the retailers' distribution roundtrips.

\section{Time-window pressure}

Changes in Time-window pressure may force retailers to alter their vehicle routing that is determined by the independent construct Logistical concept (see Figure 3), as the vehicle routing may not satisfy the governmental time-window demands. For example, because of an increase in the number of time-window affected cities, the retailer has to change the order of its visits in roundtrips. The construct Time-window pressure (see Figure 3) 
indicates the local authorities' time-window policies as they impact the Logistical concept. We manipulate this construct in the scenario analysis. Time-window pressure is determined by two dimensions:

- The number of time-window restricted areas. In the scenarios, we vary the number of cities of which the shopping areas are affected by time-windows.

- The time-window length. This is the length of the time-window, in which large vehicles are allowed in the time-window area. We vary the time-window length in different scenarios.

We incorporated the retailers' changes as a result of varying Time-window pressure by the retailers' reactions, which is discussed in a separate section later in this paper. In interviews we discussed this likely reaction that is based on their current experiences with time-window restrictions and their current reaction on these regulations. We use external factors, from the conceptual framework (see Figure 2), that are relevant for this study.

Besides the theoretical derivation of the constructs and their dimensions, we validated all constructs by confronting several logistics managers (outside the case sample), experts from academia and PSD (Dutch Platform on City Distribution) with them. This led to a slightly sharper formulation of the constructs and their dimensions, as finally formulated in Figure 3.

\section{Methodology}

We adopt a multiple case study method to address the research questions (Eisenhardt, 1989; Yin, 2003) and follow Voss et al.'s (2002) steps: cases selection, research steps and protocol development, and field research.

\section{Case selection}

Since we are interested in local authorities' urban freight policies, and these policies usually only apply to shopping centers, we limit the cases to retailers at least partially located in city centers, and not solely in peripheries. Most cities contain a similar collection of stores, with the largest share for supermarkets, department stores, fashion stores, and specialist stores (like pharmacies, drug stores, and perfumeries) (Boerkamps, 2001). Our theoretical replication procedure (Voss et al., 2002; Yin, 2003) aims at selecting cases that are affected differently by the same time-window pressure measure, but are similar in other contextual factors; e.g. they are all active (at least) in the same region, the Netherlands, and face the same policy context, have customers with similar spending power, have similar marketing activities, etc. We selected three food retailers (of which one forms two cases), four department store retailers, five fashion retailers, and one drug store retailer. Within a sector, the selected retailers differ in company strategy and dimension values. Table 2 shows the dimension values for the base scenario for all cases. The cases are labeled as follows: the first two characters represent the retailer type: drug store (DR), department store (DS), fashion (FA), and food (FO). For the food retailers the third small character represents the flow type; $d$ stands for dry groceries, $f$ for fresh products, and $d f$ for both. The next character represents the retailer's strategy: cost leader (C), differentiation (D), and response (R). The last two characters represent the case number. 
Table 2 Characteristics and initial dimension values per case for one week

\begin{tabular}{|c|c|c|c|c|c|c|c|c|c|c|c|c|c|c|c|}
\hline \multirow[b]{3}{*}{$\begin{array}{l}\mathscr{y} \\
\text { ల్ }\end{array}$} & \multicolumn{5}{|c|}{ External factors } & \multicolumn{10}{|c|}{ Logistical concept } \\
\hline & \multirow{2}{*}{\multicolumn{2}{|c|}{ 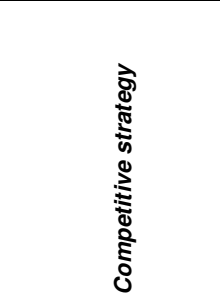 }} & \multicolumn{3}{|c|}{ Product characteristics } & \multirow[b]{2}{*}{ 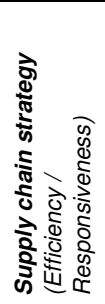 } & \multicolumn{6}{|c|}{ Network structure } & \multicolumn{3}{|c|}{ Logistical planning } \\
\hline & & & 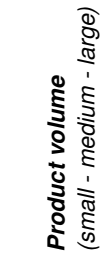 & 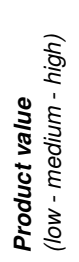 & 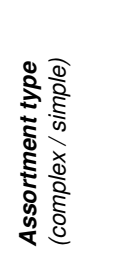 & & 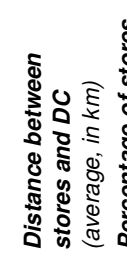 & \multicolumn{2}{|c|}{ 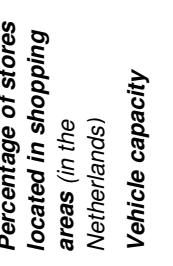 } & \multicolumn{3}{|c|}{ 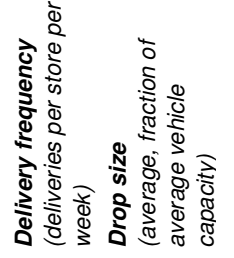 } & \multicolumn{3}{|c|}{ 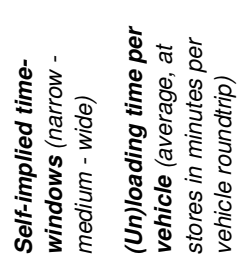 } \\
\hline DRC01 & \multicolumn{2}{|c|}{ costs } & $\mathrm{s}$ & M & S & E & 110 & $63 \%$ & 3.9 & 1.0 & \multicolumn{2}{|c|}{0.19} & M & & 64 \\
\hline DSC02 & \multirow{2}{*}{\multicolumn{2}{|c|}{$\begin{array}{l}\text { costs (discounter) } \\
\text { costs }\end{array}$}} & $\mathrm{s}$ & $\mathrm{L}$ & $\mathrm{s}$ & E & 127 & $94 \%$ & 5.6 & 1.2 & \multirow{2}{*}{\multicolumn{2}{|c|}{0.81}} & M & & 122 \\
\hline DSC03 & & & M & M & $\mathrm{s}$ & $\mathrm{E}$ & 103 & $67 \%$ & 3.5 & 2.7 & 0.42 & & M & & 115 \\
\hline DSD04 & \multicolumn{2}{|c|}{ differentiation } & L & $\mathrm{H}$ & C & $E / R$ & 76 & $81 \%$ & 4.9 & 8.1 & \multirow{2}{*}{\multicolumn{2}{|c|}{$\begin{array}{l}0.30 \\
1.00\end{array}$}} & M & & 83 \\
\hline DSD05 & \multicolumn{2}{|c|}{ differentiation } & L & $\mathrm{H}$ & C & $E / R$ & 89 & $100 \%$ & 4.9 & 5.0 & & & $\mathrm{~N}$ & & 63 \\
\hline FAC06 & c 10010 & & $\mathrm{~s}$ & M & $\mathrm{s}$ & $\mathrm{E}$ & 116 & $93 \%$ & 5.5 & 4.7 & 0.2 & & M & & 185 \\
\hline FAC07 & $\operatorname{costs}($ & liscounter & $\mathrm{s}$ & M & $\mathrm{s}$ & $\mathrm{E}$ & 198 & $53 \%$ & 5.0 & 2.0 & 0.1 & & W & & 181 \\
\hline FAR08 & & ponse & $\mathrm{s}$ & $\mathrm{H}$ & C & $\mathrm{R}$ & 103 & $98 \%$ & 1.8 & 5.0 & 0.1 & & M & & 165 \\
\hline FAR09 & & ponse & $\mathrm{s}$ & $\mathrm{H}$ & C & $\mathrm{R}$ & 86 & $92 \%$ & 1.0 & 2.0 & 0.1 & & M & & 72 \\
\hline FAR10 & & ponse & $\mathrm{S}$ & $\mathrm{H}$ & C & $\mathrm{R}$ & 102 & $97 \%$ & 2.6 & 2.0 & 0.1 & & W & & 256 \\
\hline FOdC11 & costs ( & liscounter & M & L & S & E & 71 & $39 \%$ & 4.9 & 2.9 & 0.8 & & M & & 47 \\
\hline FOdD12 & differ & entiation & M & L & S & $E / R$ & 42 & $47 \%$ & 4.7 & 4.9 & 0.7 & & M & & 78 \\
\hline FOdfC 13 & costs (so & $t$ discount & ter) & L & C & $\mathrm{E}$ & 32 & $48 \%$ & 3.0 & 21.5 & 0.9 & & M & & 17 \\
\hline FOfD14 & differ & entiation & S & M & C & $E / R$ & 42 & $47 \%$ & 4.9 & 10.7 & 0.1 & & M & & 134 \\
\hline & & & Distrib & tinn & rmance & & & & & & & & & & \\
\hline & & Opera & ational & & Financial & $E n v i$ & ironmental & & & Case & charac & teristic & & & \\
\hline 心 & 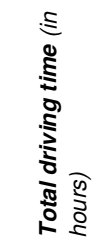 & 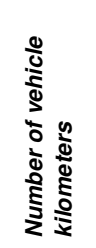 & 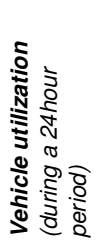 & 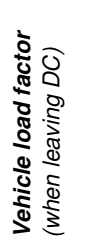 & 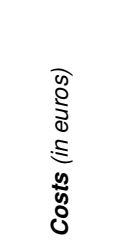 & & 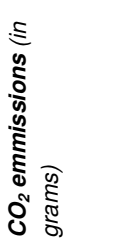 & & 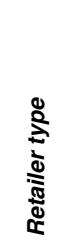 & & 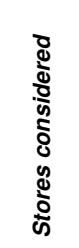 & 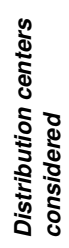 & 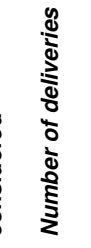 & 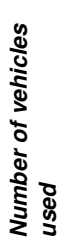 & 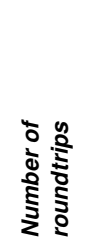 \\
\hline DRC01 & & 28535 & $27 \%$ & $93 \%$ & 26581 & & $.7 \mathrm{E}+07$ & & drug & & 498 & 1 & 515 & 20 & 96 \\
\hline DSC02 & 380 & 27097 & $40 \%$ & $90 \%$ & 38961 & & $2.0 \mathrm{E}+07$ & depa & irtment & store & 106 & 1 & 132 & 15 & 107 \\
\hline DSC03 & 1074 & 9323 & $34 \%$ & $91 \%$ & 73927 & & $3.8 \mathrm{E}+07$ & depa & irtment & store & 275 & 1 & 791 & 42 & 331 \\
\hline DSD04 & 797 & 50793 & $30 \%$ & $87 \%$ & 57377 & & $3.4 \mathrm{E}+07$ & depa & irtment & store & 93 & 4 & 751 & 34 & 224 \\
\hline DSD05 & 144 & 9361 & $21 \%$ & $90 \%$ & 15683 & & $.3 E+06$ & depa & irtment & store & 13 & 1 & 68 & 11 & 68 \\
\hline FAC06 & 536 & 33531 & $36 \%$ & $93 \%$ & 39984 & & $2.2 E+07$ & & fashior & & 108 & 1 & 510 & 22 & 121 \\
\hline FAC07 & 717 & 38573 & $62 \%$ & $96 \%$ & 40549 & & $2.7 \mathrm{E}+07$ & & fashior & & 475 & 1 & 952 & 28 & 105 \\
\hline FAR08 & & 33610 & $38 \%$ & $94 \%$ & 39715 & & $.5 \mathrm{E}+07$ & & fashior & & 180 & 1 & 900 & 23 & 109 \\
\hline FAR09 & 164 & 9849 & $27 \%$ & $93 \%$ & 9279 & & $3.8 \mathrm{E}+06$ & & fashior & & 122 & 1 & 244 & 8 & 34 \\
\hline FAR10 & 166 & 9363 & $45 \%$ & $80 \%$ & 12189 & & 1.2E+06 & & fashior & & 133 & 1 & 266 & 7 & 26 \\
\hline FOdC11 & 403 & 26677 & $42 \%$ & $90 \%$ & 33167 & & $.3 \mathrm{E}+07$ & food (c & dry gro & ceries) & 77 & 1 & 224 & 18 & 185 \\
\hline FOdD12 & 696 & 41993 & $32 \%$ & $90 \%$ & 75139 & & $3.8 \mathrm{E}+07$ & food (C & dry gro & ceries) & 134 & 1 & 663 & 27 & 498 \\
\hline FOdfC13 & 839 & 50721 & $31 \%$ & $90 \%$ & 61947 & & $1.3 \mathrm{E}+07$ & $\begin{array}{l}\text { food }(d r) \\
\text { fre }\end{array}$ & $\begin{array}{l}\text { y groce } \\
\text { sh goo }\end{array}$ & $\begin{array}{l}\text { eries and } \\
\text { ds) }\end{array}$ & 38 & 1 & 820 & 30 & 782 \\
\hline FOfD14 & 423 & 24286 & $26 \%$ & $97 \%$ & 42332 & & 2. $2 \mathrm{E}+07$ & food & fresh 9 & goods) & 134 & 1 & 1431 & 43 & 227 \\
\hline & & & & & & & & & & & 2386 & 17 & 8267 & 328 & 2913 \\
\hline & & & & & & & & & & & & otal in & this cas & e study & \\
\hline
\end{tabular}

We included only those foreign stores that were really interweaved with Dutch stores, in one roundtrip or in one vehicle during a day, since we only manipulate Time-window pressure in the Netherlands. This applies to cases DSC02, DSC03, and FAC07 (see Table 2) that have German and Belgian stores. All retailers use a weekly repetitive distribution scheme, except cases DSD04 and DSC02, who use 2- and 4-week repeating schemes, respectively. The scenario results are all recalculated per week. For retailer DSD04 we considered all stores supplied from the one national distribution center, including the deliveries from the three regional distribution centers to the same stores. DSD04's nightly cross-dock activities between the different distribution centers are not considered in this study. Although cases FOfD14 and FOdD12 (see Table 2) are owned by the same mother company, their assortment type differs and therefore they have separate delivery flows. 
We only consider the deliveries from a retailer's distribution center to its stores. Some retailers use, in the current situation, direct deliveries for a small percentage of special goods. However, the percentage of direct deliveries is at most $10 \%$ of the delivered goods.

\section{Research protocol}

In order to improve the data reliability we developed a research protocol (see Appendix A) before we started to collect data (Yin, 2003). This research protocol ensures that the data collection procedures can be repeated with the same results. All information was received in full, except for cost information, which some retailers were not willing to provide, because of confidentiality.

\section{Scenario-definition}

We designed four main scenarios. Based on the retailer's current operations (today'sscenario), we designed the base scenario by removing all governmental time-windows that apply to the stores (scenario 0). The difference between today's scenario and scenario 0 reflects the consequences of today's time-window restrictions on the retailers' distribution. Scenarios 1 and 2, in which we manipulated the time-window pressure, are compared with the base scenario (scenario 0)

In scenario 1 we vary both the number of cities with time-windows and the timewindow lengths. We distinguish 18 sub scenarios (see Table 3). A column in Table 3 represents different time-window lengths, whereas a row represents an increasing number of cities with such a time-window restriction, based on the city size (number of inhabitants). In 2002, time-windows in the Netherlands started on average at 6.53AM and ended at 11.18AM (PSD, 2002). We distinguish three time-window lengths: scenarios 1A (from 6.00AM to 12.00AM), 1B (from 6.30AM to 11.00AM), and 1C (from 7.00AM to 10.00AM). Varying the number of cities with time-windows in the sub scenarios implies that retailers are influenced differently (see Figure 4). This scenario covers the most plausible range of time-window restrictions in which the retailers' reactions are still reliable; if the time-window length would be less than three hours some retailers indicated that they would no longer be able to supply their stores. A time-window length of more than 6 hours (scenario 1A), would be more or less equal to most of the retailer's self-implied time-windows, so similar to today's scenario.

Table 3 Scenario 1 defined

\begin{tabular}{lllllll} 
Cities affected & $\begin{array}{c}\text { Only } 5 \text { largest } \\
\text { cities in the } \\
\text { Netherlands }\end{array}$ & $\begin{array}{c}\text { Only } 10 \text { largest } \\
\text { cities in the } \\
\text { Netherlands }\end{array}$ & $\begin{array}{c}\text { Only } 25 \text { largest } \\
\text { cities in the } \\
\text { Netherlands }\end{array}$ & $\begin{array}{c}\text { Only } 50 \text { largest } \\
\text { cities in the } \\
\text { Netherlands }\end{array}$ & $\begin{array}{c}\text { Only } 100 \text { largest } \\
\text { cities in the } \\
\text { Netherlands }\end{array}$ & $\begin{array}{c}\text { Only } 250 \text { largest } \\
\text { cities in the } \\
\text { Netherlands }\end{array}$ \\
\hline $\begin{array}{l}\text { Time windows } \\
\text { 6:00-12:00AM }\end{array}$ & Sc1-A1 & Sc1-A2 & Sc1-A3 & Sc1-A4 & Sc1-A5 & Sc1-A6 \\
$\begin{array}{l}\text { Time windows } \\
\text { 6:30-11:00AM }\end{array}$ & Sc1-B1 & Sc1-B2 & Sc1-B3 & Sc1-B4 & Sc1-B5 & Sc1-B6 \\
$\begin{array}{l}\text { Time windows } \\
\text { 7:00-10:00AM }\end{array}$ & Sc1-C1 & Sc1-C2 & Sc1-C3 & Sc1-C4 & Sc1-C5 & Sc1-C6
\end{tabular}

In practice, different municipalities employ different access time-windows that often overlap. National governments are interested to harmonize the different local regulations 
(Lemstra, 2004; OECD, 2003). Time-windows can be harmonized in different ways. We define scenario 2 with window sizes gradually decreasing with the city size (PSD, 2001): the shopping areas in the five largest cities in the Netherlands have a time-window of only three hours (which is similar to sub scenario $1 \mathrm{C} 1$ ), the sixth to the 25th largest city have a time-window of 4.5 hours (similar to sub scenarios $1 \mathrm{~B} 2$ and $1 \mathrm{~B} 3$ ), and the 26th to the 100th largest city have a time-window of 6 hours (similar to sub scenarios 1A4 and 1A5). This results in an average time-window size of 4 hours and 53 minutes for the time-window affected cities.

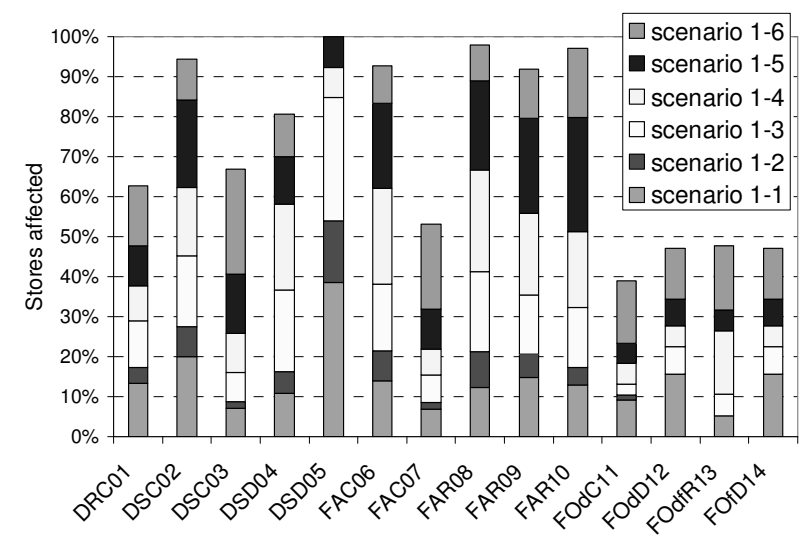

Figure 4 Cumulative percentage of stores affected per case per sub scenario

\section{Vehicle route calculation}

To calculate the impact of the different scenarios on the retailers' distribution costs and environmental burden, we have to solve a number of vehicle routing problems with timewindows (VRPTW). This problem has been studied widely in literature (see e.g. Braysy and Gendreau, 2005a, 2005b). Based on the retailers' reactions we planned new roundtrips for all scenarios. In some scenarios, extra vehicles have to be added to supply all stores in time. Extra vehicles operate at the same costs as the current vehicle fleet. The first step in making a new planning is minimizing the necessary vehicle fleet. For this purpose and for solving the VRPTW for each retailer we use SHORTREC 7.0 software, developed by Ortec Consultants (see e.g. Hall, 2004). SHORTREC 7.0 uses two algorithms; a route construction algorithm: a greedy order-to-route assignment algorithm to generate initial roundtrips, and an iterative 2-OPT-like improvement algorithm. From the new retailers' roundtrip plannings we can find the operational performance dimensions for all (sub) scenarios. In fact, SHORTREC is used by several of the retail organizations involved.

\section{Retailers' reactions}

The retailers can only make changes in their roundtrip planning on tactical and operational level (see Figure 3), which implies a time horizon of less than a year (Ballou, 1992; Crainica and Laporte, 1997). More radical changes would decrease the likelihood of the reaction to occur in reality. Some retailers indicated to continue delivering outside the time-windows and then see whether there is supervision or not. Other initial reactions were to ask for dispensation at the local authorities. In this study we assumed that it would not be possible to get dispensation and that there would be sufficient supervision on compliance with the time-window restrictions. Under these assumptions the retailers' 
reactions are comparable. The retailers change the sequence of the stores in a roundtrip to plan a time-window affected store earlier in the roundtrips. In case it is necessary, they use extra vehicles during the time-window period. This implies that the number of drops in a roundtrip can decrease as the Time-window pressure increases. Still there are slight differences, depending on specific retailer characteristics. For example, one food retailer wants to supply fresh bread to all stores, affected or not, every morning. This retailer adapts its vehicle routing to supply the affected stores as early as possible in the timewindow period, without compromising the bread deliveries. In case the time-window restriction causes an impossibility to deliver all stores with the current vehicle fleet, all retailers prefer using extra vehicles over contracting out the entire distribution process, or over moving the store to the city periphery. Some retailers already use third-party logistics vendors in their current way of supplying their stores, however they always keep the full process control and develop at most an arm's length relationship with a thirdparty logistics (Paché, 1998; Razzaque and Sheng, 1998). Combining loads with other retailers is also not an option, in view of the high truck load factor and the extra efforts this would take.

\section{Validation and reliability}

We distinguish two types of validation. The first is model validation; we validated each retailer's current one week planning by recalculating it with SHORTREC 7.0. The maximum difference was $5 \%$ in the number of vehicle kilometers, the total time used for the distribution, the number of vehicles used, and the total transport costs to supply all stores. In addition, the detailed results were also checked with the retailers' planners. We also evaluated the results of all scenarios with the planners. We conclude that the model used is valid and that the results from solving the VRPTW are sufficiently reliable to base conclusions on them. Second, we address the general issues in validity and reliability (as summarized in Table 4) in various ways (see e.g. Voss et al., 2002; Yin, 2003).

Table 4 Validity and reliability

\begin{tabular}{ll}
$\begin{array}{l}\text { Type of } \\
\text { validity }\end{array}$ & Methods of addressing validity and reliability issues in this case study \\
\hline $\begin{array}{l}\text { Construct } \\
\text { validity }\end{array}$ & - Constructs are determined by main decisions (according to literature) retailers have to \\
& make in designing the issue in question \\
& - Independent experts feedback \\
- Triangulation of questionnaire and interview data with the retailer's transport planning & Model is validated with retailers (interviews) as well as with transport planning (company \\
& documents)
\end{tabular}




\section{Results and discussion}

Previous studies (e.g. Allen et al., 2004; Groothedde and Uil, 2004) only focus on the immediate effects of time-window policies. The within-case analysis shows some interesting insights in how these effects are realized. The cross-case analysis shows that there are distinct differences in the cost-sensitivity of retailers to an increase in timewindow pressure.

\subsection{Within-case analysis and discussion}

To answer the first research question we use within-case analysis (Eisenhardt, 1989). First we show the distribution performance impacts of today's time-window restrictions for all cases individually. Figure 5 shows the percentage cost increase to supply a timewindow affected store. These costs are on average 12\% higher than in case the store would not be affected by this restriction. The cases are affected very different by today's Time-window pressure.

We present only the overall aggregate results (i.e. summed over all retailers) for the different time-window pressure scenarios (for space reasons), although the individual results differ as much as those in Figure 5. The graphs in Figure 6 show both Timewindow pressure's dimensions and each shows one Distribution performance dimension. The $x$-axis shows the number of time-window restricted areas, as the percentage of stores affected. The time-window length is presented by three lines; the dotted line shows scenario 1A (time-window length of 6 hours), the straight line scenario 1B (time-window length of 4.5 hours), and the dashed line scenario 1C (time-window length of 3 hours). Scenario 2 is depicted by a single rhomboid point.

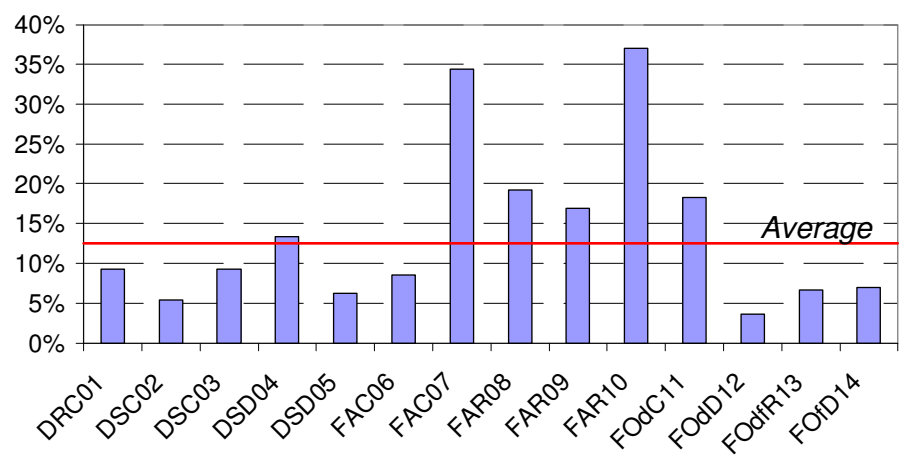

Figure 5 Today's cost-increase for a time-window affected store

Figure 6 shows the development of the average load factor, the average vehicle utilization, the distribution costs, and the $\mathrm{CO}_{2}$ emissions (cumulated over all retailers) as a function of Time-window pressure. Graphs of the other two Distribution performance dimensions show a similar pattern as the financial and environmental performance. The figure shows that an increasing number of time-window restricted areas leads to an increase in the distribution costs and the environmental burden. This is caused by an increase in the number of roundtrips, the total driving time and the number of vehicle kilometers. The decrease in time-window length leads to an increase in costs and environmental burden as well. The consequences of increasing Time-window pressure are 
higher if more stores are affected. If more than about $30 \%$ of the stores are affected by a time-window the increase in impacts is considerable.
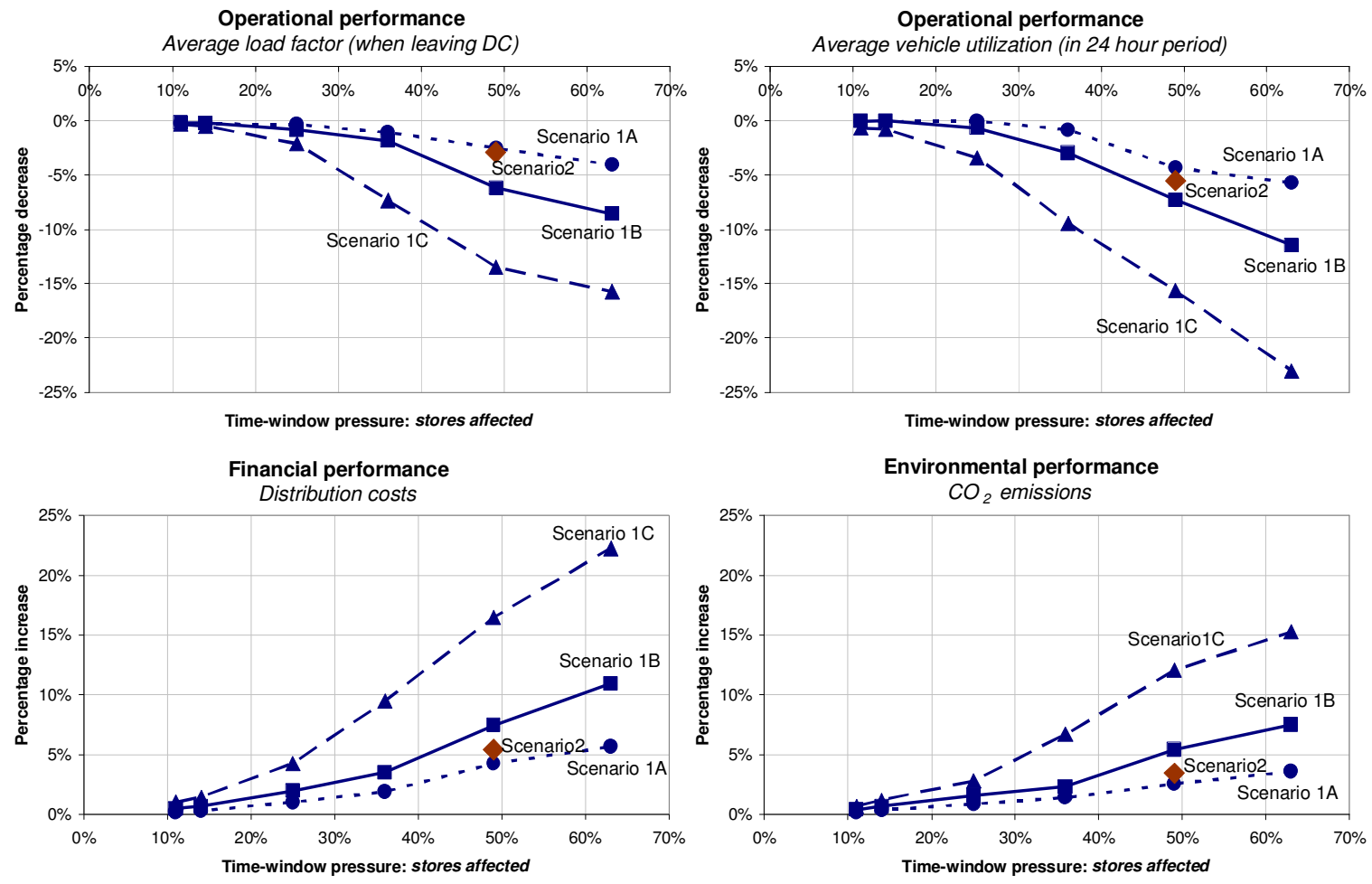

Figure 6 Distribution performance as function of Time-window pressure

Figure 6 shows that, although the difference in time-window length between scenarios $1 \mathrm{~A}$ and $1 \mathrm{~B}$ (1.5 hours) equals the difference in time-window length between scenarios 1B and $1 \mathrm{C}$, the increase of the impacts (and decrease for vehicle utilization and vehicle load factor) is at least two times larger between scenario $1 \mathrm{~B}$ and $1 \mathrm{C}$, than between $1 \mathrm{~A}$ and $1 \mathrm{~B}$. The impacts of time-windows apparently increase substantially, if the time-windows become tighter. For example, the cost increase in scenario $1 \mathrm{~A} 6$ is almost $6 \%$ if the timewindow length is reduced by 1.5 hours, but almost $11 \%$ in scenario $1 \mathrm{~B} 6$. If we decrease the time-window length again by 1.5 hours we notice a cost increase of more than $22 \%$ (nearly four times the increase of scenarios 1A6). Local authorities (or national governments) should therefore be careful by determining the time-window length, as reducing it increases the impacts considerably. Especially for narrow time-windows restriction (scenario $\mathrm{C}$ ), the increase in the number of used vehicles necessary to supply all stores is considerable, resulting in a decrease in vehicle utilization over a 24-hours period.

In scenario 2, the time-window lengths gradually decrease with the municipality size. In this scenario, $49 \%$ of the retailers' stores are affected by an average time-window restriction of 4 hours and 53 minutes (11\% of the stores has a three-hour time-window, $14 \%$ has a 4.5 hours time-window, and $24 \%$ of the stores has a time-window of six hours). In all graphs, scenario 2 is very close to scenario 1A5, in which all $49 \%$ of the affected stores have a time-window of six hours. One would expect that scenario 2 is closer to scenario 1B5 (with a length of 4.5 hours) than to $1 \mathrm{~A} 5$. We conclude that 
harmonized time-windows perform better for both the retailers and the environment, than uniform (and fully coinciding) time-windows with similar pressure. This complies with Lemstra (2004) and OECD (2003) who give a similar advice.

\subsection{Cross-case analysis and discussion}

To answer the second research question we use a cross-case analysis (Eisenhardt, 1989). We examine the independent constructs successively. The cost-increase of retailers using a responsive supply chain strategy is slightly higher than that of retailers that use an efficient supply chain strategy as governmental time-window pressure increases. The retailers using a responsive supply chain strategy are all fashion retailers and these are most cost-sensitive to increasing time-window pressure. Efficiency-orientated retailers (representatives can be found in any sector in our study) are affected more than the retailers with a mixed supply chain strategy.

For every Logistical concept dimension, we distinguish four case groups, so that all groups contain at least three cases, on which the dimension values vary form very low to very high (see Table 5). We sort the cases by increasing dimension value. The first group consists of the three cases with the lowest dimension value, the second and third groups each consist of the next following four cases, and the fourth group contains the last three cases with the highest dimension value. Table 5 shows the resulting boundaries per dimension group and the number of cases per group. For all dimensions, except for delivery frequency and self-implied time-windows, the cases are divided in a similar way. For delivery frequency the first group consists of the five cases with two deliveries per store per week or less (putting only three cases with the lowest dimension's value, as we did for the other dimensions, would be arbitrary, as three cases have a same dimension value). This leaves three cases per group for the remaining groups. The supply chain strategy and the dimension self-implied time-windows is measured on a 3-point scale (see section 2), resulting in 3 case groups. The cases appear to be divided partly identical for unloading time per vehicle and drop size (seven cases in the same groups), and for unloading time per vehicle and distance between distribution center and stores (eight cases in the same group). We already mentioned the relation between drop size and unloading time per vehicle in section 2 . The similarity between the dimensions unloading time per vehicle and distance between distribution center seems to be coincidental.

Table 5 Groups defined per Logistical concept dimension value

\begin{tabular}{lcccc} 
& VERY LOW & LOW & HIGH & VERY HIGH \\
& 3 cases & 4 cases & 4 cases & 3 cases \\
\hline vehicle capacity & $<3.0$ & $3.0-4.8$ & $4.8-4.95$ & $>4.95$ \\
distance between DC - stores & $<50$ & $50-100$ & $100-115$ & $>115$ \\
stores located in shopping areas & $<48 \%$ & $48 \%-70 \%$ & $70 \%-95 \%$ & $>95 \%$ \\
unloading time per vehicle & $<64$ & $64-100$ & $100-180$ & $>180$ \\
drop size & $<0.13$ & $0.13-0.29$ & $0.29-0.82$ & $>0.82$ \\
- & $<2.1$ & $2.1-4.8$ & $4.8-8.0$ & $>8.0$ \\
delivery frequency & (5 cases) & (3 cases) & (3 cases) & (3 cases) \\
self-implied time windows & narrow (2 cases) & medium (11 cases) & wide (1 case)
\end{tabular}


To examine the effects of different decisions in the Logistical concept we vary its dimensions between very high to very low for a constant time-window length of three hours (scenario 1C). Figure 7 shows the cost-increase impacts. The pattern does not change by varying the time-window length, but the impact magnitude does. For all dimensions Figure 7 shows that if the values are high the cost-sensitivity of the retailers is high is well, except for the delivery frequency, which shows an opposite pattern. For the vehicle capacity we did not find a pattern.
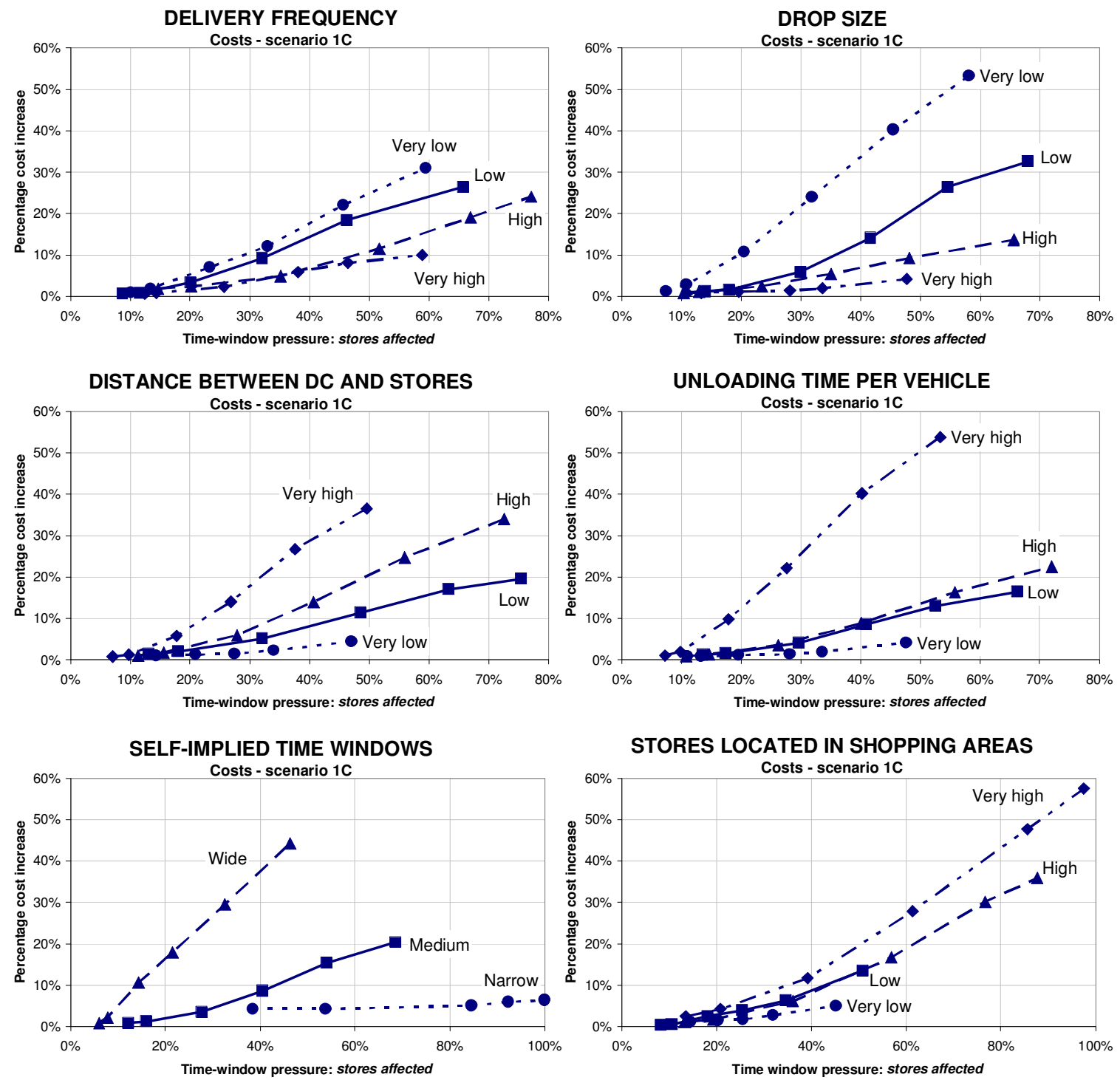

Figure 7 Varying Time-window pressure impacts for different Logistical concept dimensions values

Most of the results in Figure 7 are intuitive. The cost-impact of the time-window pressure increases as the distance between the DC and the stores increases. The graph for the dimension drop size clearly indicates that retailers with a small drop size are affected most by time-windows. Retailers with small drops combine them for many different stores per roundtrip face a considerable increase in the number of roundtrips and a decrease in the number of stores that can be combined in one roundtrip, as Time-window 
pressure increases. To make these extra roundtrips, an increase in the vehicle fleet is necessary, which immediately leads to a cost increase. Retailers with a short unloading time per vehicle, including the one using swap bodies, are affected least by increasing time-window pressure. For a same percentage of time-window affected stores, retailers with many stores located in shopping areas have a slightly higher cost increase than retailers with fewer stores in such shopping areas. This might seem unexpected, as these retail groups feel the same Time-window pressure. This is caused by the fact that the stores located in shopping areas have on average longer (un)loading times. This is mainly due to other urban freight policies that are effective in these areas (e.g. vehicle restrictions) and the fact that some of these areas include pedestrian areas, in which, even during the time-window period, no vehicles are allowed, or in which vehicles simply cannot come. Although these areas may be quite small, the driver has to walk longer distances with the roll containers than in other areas. The higher the delivery frequency the lower the cost-increase caused by increasing time-window pressure. Retailers with a high delivery frequency have in general short distances between the DC and the stores. The retailers that have a very high delivery frequency have either so much affected stores every day that they can combine these stores in a roundtrip during the time-window period, or have mainly point-to-point deliveries (full-truck-loads), in which case the number of vehicle kilometers hardly changes by an increase in time-window pressure.

We can conclude from the above that, in order to be relatively insensitive to timewindow pressure, a retailer has to use the time-window period as efficiently as possible. This implies that the retailer should try to reduce (un)loading time at the stores, traveling large distances, and combining too many stores in one vehicle roundtrip. However, some trade-offs have to be made: most measures that reduce a retailer's cost-sensitivity to timewindow pressure add cost. Implying tighter time-windows than the governmental ones decreases time-window sensitivity, but potentially leads to transportation cost increase (although this might be offset by a store-operation cost reduction). Shortening the distance between the distribution center and stores can improve time-window insensitivity, but adding extra distribution centers certainly adds costs. Locating stores outside shopping areas contradicts many retailers' corporate strategies. Using the vehicles as efficiently as possible during a day may be cost efficient, but it leads to an increase in time-window sensitivity. It appears to be difficult to combine insensitivity to timewindow pressure and cost efficiency. The main results are summarized as follows:

- An increase in Time-window pressure, by either an increase in the number of time-window restricted areas or a decrease in the time-window length, causes a rise in distribution costs and environmental burden.

- The increase in distribution costs and environmental burden increases considerably (more than linear) if the time-window length decreases.

- Harmonizing time-window policies between different local authorities has a positive impact on retailer's distribution costs and environmental burden.

- Retailers that use a responsive supply chain strategy are affected most by an increase in Time-window pressure. Retailers with a focus on efficiency in their supply chain strategy are more cost-sensitive to time-windows than the retailers that have a mixed supply chain strategy.

- The retailer's cost-sensitivity to time-windows is positively related to dimensions in the logistical concept on: 
$\circ$ the distance between stores and the distribution center

$\circ$ the (un)loading time per vehicle

$\circ$ the self-implied time-windows

$\circ$ the percentage of stores located in shopping areas

and negatively related to dimensions in the logistical concept on:

$\circ$ the drop size

$\circ$ the delivery frequency.

- The retailer's-cost sensitivity to time-windows is lowest in case all activities performed during the time-window period are done in a minimum time period.

\section{Conclusion and implications}

Access time-window restrictions are implemented by many municipalities to improve social sustainability elements like noise reduction, visual intrusion, and hinder for citizens. Obviously, outside the time-window period the human exposure to large vehicle's noise and emissions is reduced to zero and the pedestrian safety is improved in the time-window area, as there simply are no large vehicles. The improvement of these social sustainability issues in the shopping areas goes along with deteriorating environmental and financial performance. Allen et al. (2003) argue that the number of vehicle kilometers and total driving time indicate impacts on visual intrusion and safety. In that case we can conclude that these objectives are not met. Furthermore, timewindows cause an increase in the inefficient use of the vehicle fleet, which implies extra social costs for inefficiency of operations. During the time-window hours negative impacts still occur in time-window areas, albeit felt by fewer people that are shopping, as the time-windows mostly do not correspond with shopping hours. The time-window period corresponds with especially the morning rush, so it may add to accessibility problems during that period. Although these objectives are achieved to a certain extent, time-windows simultaneously bring strong negative impacts on economic and environmental sustainability.

We found that these time-windows cause an increase in the amount of $\mathrm{CO}_{2}$ emissions. Time-windows also cause an increase in retailers' distribution costs. When time-window lengths decrease, the financial and environmental performance deteriorates even more. The total percentages increase in both costs and emissions depend on the retailer's logistical concept and the exact time-window pressure. If less than $30 \%$ of the stores are affected, increases are in general moderate (less than 6\%). When $60 \%$ of the stores are affected, cost-increases vary from $5 \%$ (scenario 1A) to $20 \%$ (scenario 1C) and emission increases vary between $4 \%$ (scenario $1 \mathrm{~A}$ ) and 15\% (scenario 1C). Governmental bodies considering time-window restrictions should therefore be careful in determining the timewindow length.

Harmonization of time-access windows between different municipalities results in lower costs for the retailers and lower global environmental impacts than independent, coinciding time-windows.

This study provides transportation and operations managers with clear insights in the organization of urban area store distribution, in order to coop with increasingly restrictive time-window policies and negative transport effects. First, it shows how they can deal with increasing Time-window pressure. The impact of increasing time-window pressure 
varies for different retailers. The retailers succeeding in making very short stops, for example by using detachable swap bodies or by reserving extra staff to help unloading the vehicles are affected less than retailers that have a long (un)loading time. Retailers that have a short travel distance between the stores and the distribution center are affected less by time-windows than those that have to travel a long distance. These dimensions show that supplying more stores during the time-window hours enabled by short distance, short unloading time, and larger drop size, reduces sensitivity to time-window pressure. Furthermore, retailers that use their vehicles most during a 24-hours period in the current situation are affected worst by time-windows. Most actions a retailer can undertake to reduce time-window pressure sensitivity, increase distribution costs (or decrease the retailer's service level). Second, this study can be used by managers in discussions with local authorities on developing more sustainable urban freight transport and less restrictive policy packages to achieve this.

The research framework and the research method that we introduced in this study could be used to examine other local authorities' sustainability policy measures or policy packages as well, for example more possibilities for harmonizing time-windows.

As with most empirical studies, there are some limitations of the present research. The multiple case study approach limits the generalizibilty of this study's findings. Although we use fourteen cases, the size of this sample is too small to consider any statistical analysis. However, even though all cases are Dutch, we deem the results to be valid for the entire Western European context. The findings may not hold for a broader context. However, the summarized results, at the end of paragraph 4, can be used in further research with a larger sample size, to be tested and refined. In this paper we already studied more than 2300 stores that are supplied with over 8200 drops in almost 3000 roundtrips during one week. To collect detailed data of a sample sufficiently large for hypotheses testing would be an enormous effort.

\section{Appendix A. The research protocol}

Our research data acquisition process consists of four steps:

1. Open interviews with the retailer's distribution or logistics manager, to collect general company information, information on the current distribution operation, and the likely reaction to different time-window policy measures. The interviews focused on the following subjects:

- Current distribution strategy

- Organization of distribution to the stores

- Choices (and explanation of choices) in the distribution strategy

In- or outsourcing activities

○ Transport conditions

- Return logistics (from stores to distribution center)

- Service levels

- Retailer's experiences with governmental urban access measures and the problems that retailers face in distribution in urban areas.

- Likely reaction on urban-access policy measures 
We presented the different scenarios to the retailers and asked for their likely reaction, based on their current distribution strategy and their reaction on current time-windows.

If possible we also interviewed retailers' physical distribution specialists and discussed their distribution planning and restrictions extensively.

2. A questionnaire to collect detail operational data, including information on

- the distribution center (e.g. location, opening hours, layout, number of dock doors (for ingoing as well as outgoing vehicles), store ordering patterns, push and pull flows)

- the stores (e.g. locations, sales floor area, turnover indication, loading and unloading process and times, self-implied restrictions (and the reasons), governmental (or other external) restrictions, supply flow data expressed in product carriers (roll cages, pallets) per week, staff presence, and number of deliveries per week).

- the vehicle fleet (e.g. vehicle types, number of vehicles per type, (un)loading process and times per vehicle at the DC and stores, capacity, weight, length, height, number of axles, engine type (EURO I-IV), driver's working times (normal as well as maximum overworking times), driver's breaks, operating costs (fixed and variable per hour and kilometer)).

- the product carriers (type: e.g. pallets, or roll cages, and average (un)loading time per product carrier).

3. Company documents and additional information. Company documents contain (at least) the retailer's entire transport planning for one week. Next to that, all distribution centers were visited.

4. Finally, in case of indistinctness or if extra information was necessary we contacted the retailers by telephone or by e-mail.

\section{References}

Allen, J., Anderson, S., Browne, M. and Jones, P., 2000. A framework for considering policies to encourage sustainable urban freight traffic and goods / service flows; summary report. Transport Studies Group, University of Westminster, London

Allen, J., Browne, M., Tanner, G., Anderson, S., Chrisodoulou, G. and Jones, P., 2004. Analysing the Potential Impacts of Sustainable Distribution Measures in UK urban areas, in: E. Taniguchi and R.G. Thompson (Ed.), Logistics Systems for Sustainable Cities, proceedings of the 3rd international conference on City Logistics, Elsevier, Amsterdam, 251-262

Allen, J., Tanner, G., Browne, M., Anderson, S., Chrisodoulou, G. and Jones, P., 2003. Modelling policy measures and company initiatives for sustainable urban distribution; Final Technical Report. Transport Studies Group, University of Westminster, London

Anderson, S., Allen, J. and Browne, M., 2005. Urban logistics - how can it meet policy makers' sustainability objectives? Journal of Transport Geography 13 (1), 71-81

Ballou, R.H., 1992. Business Logistics Management. Prentice Hall International, London

Banister, D., 2000. Sustainable urban development and transport: A Eurovision for 2020. Transport Reviews 20 (1), 113-130

Banister, D., Stead, D., Steen, P., Akerman, J., Dreborg, K., Nijkamp, P. and Schleicher-Tappeser, R., 2000. European Transport Policy and Sustainable Mobility. Spon Press, London

Boerkamps, J., 2001. State-of-the-art of city logistics in the Netherlands: research framework and research activities, in: E. Taniguchi and R.G. Thompson (Ed.), City Logistics II. Institute of Systems Science Research, Kyoto, 241-254 
Braysy, O. and Gendreau, M., 2005a. Vehicle Routing Problem with Time Windows, Part I: Route Construction and Local Search Algorithms. Transportation Science 39 (1), 104-118

Braysy, O. and Gendreau, M., 2005b. Vehicle Routing Problem with Time Windows, Part II: Metaheuristics. Transportation Science 39 (1), 119-139

Browne, M. and Allen, J., 1999. The impact of sustainability policies on urban freight transport and logistics systems, in: H. Meermans, E. Van De Voorde and W. Winkelmans (Ed.), 8th World Conference on Transport Research (WCTR), Elsevier, Antwerp, 505-518

CEC (Commission of the European Communities), 2001a. European Transport Policy for 2020: Time to Decide. Office for Official Publications of the European Communities, Luxembourg

CEC (Commission of the European Communities), 2001b. A Sustainable Europe for a Better World: A European Strategy for Sustainable Development. Office for Official Publication of the European Communities, Luxembourg

Chen, I.J. and Paulraj, A., 2004. Towards a theory of supply chain management: the constructs and measurements. Journal of Operations Management 22 (2), 119-150

Chopra, S., 2003. Designing the distribution network in a supply chain. Transportation Research Part E 23 (2), 123-140

Chopra, S. and Meindl, P., 2004. Supply chain management - strategy, planning, and operations. Pearson Prentice Hall, New Jersey

Crainica, T.G. and Laporte, G., 1997. Planning models for freight transportation. European Journal of Operational Research 97 (3), 409-438

Crainica, T.G., Ricciardib, N. and Storchib, G., 2004. Advanced freight transportation systems for congested urban areas. Transportation Research Part C: Emerging Technologies 12 (2), 119-137

Crum, B. and Vossen, M., 2000. Knelpunten in de binnenstadsdistributie, inventarisatie van de beschikbare kennis en ervaringen. Research voor Beleid (in opdracht van de MDW-werkgroep Binnenstadsdistributie), Leiden

Dawson, J., 2005. Output Considerations in Retail Productivity. International Review of Retail, Distribution \& Consumer Research, 15 (3), 337-349

De Koster, M.B.M., 2003. Distribution strategies for online retailers. IEEE Transactions on Engineering Management 50 (4), 448-457

De Koster, M.B.M., 2002. The logistics behind the enter click, in: A. Klose, M. Grazia Speranza and L.H. Van Wassenhoven (Ed.), Quantitative approaches to distribution logistics and supply chain management. Springer, Berlin, 131-148

De Koster, M.B.M. and Neuteboom, A.J., 2001. The logistics of supermarket chains: a comparison of seven chains in the Netherlands. Elsevier Business Information, Doetichem

DETR (Department of Environment, Transport and Regions), 1999. Sustainable Distribution: A Strategy. DETR, London

DETR (Department of Environment, Transport and Regions), 1998. A New Deal for Transport: Better for Everyone. The Stationery Office, London

EEA (European Environmental Agency) 2001. TERM 2001: Indicators tracking transport and environment integration in the European Union. Office for Official Publication of the European Communities, Luxembourg

Eisenhardt, K.M., 1989. Building theory from case study research. Academy of Management Review 14 (4), 532-550

Feitelson, E., 2002. Introducing environmental equity dimensions into the sustainable transport discourse: issues and pitfalls. Transportation Research part D 7 (2), 99-118

Fisher, M.L., 1997. What is the right supply chain for your product? Harvard Business Review 83-93

Geerards, J. and De Vrij, B., 1999. Kostenbesparing met wissellaadbakken in de distributie, in: J.P. Duijker et al. (Ed.), Praktijkboek Magazijnen en Distributiecentra. Kluwer, Deventer, 3.5.E-01 - 03.05.E-16,

Groothedde, B. and Uil, K., 2004. Restrictions in City-Distribution and a Possible Alternative Using the Citybox, in: P.H.L. Bovy (Ed.), A World of Transport, Infrastructure and Logistics, 8th TRAIL Congress 2004, DUP Science, Delft, 1-16

Hall, R., 2004. Vehicle Routing Software Survey. OR/MS Today 31 (3), 1-13

Heizer, J. and Render, B., 1999. Principles of Operations Management. Prentice Hall, New Jersey

Hill, M., 2001. Sustainability, greenhouse gas emissions and international operations management. International Journal of Operations \& Production Management 21 (12), 1503 - 1520 
Himanen, V., Lee-Gosselin, M. and Perrels, A., 2004. Impacts of Transport on Sustainability: Towards an Integrated Transatlantic Evidence Base. Transport Reviews 24 (6), 691-705

Keller, S.B., Savitskie, K., Stank, T.P., Lynch, D.F. and Ellinger, A.E., 2002. A summary and analysis of multi-item scales used in logistics research. Journal of Business Logistics 23 (2), 83-281

LaLonde, B.J. and Zinszer, P.H., 1976. Customer Service: Meaning and Measurement. IL: National Council of Physical Distribution Management, Chicago

Lee, H.L., 2002. Aligning Supply Chain Strategies with Product Uncertainties. California Management Review 44 (3), 105-119

Lemstra, W., 2004. Stedelijke distributie: Samen gaan voor resultaat. Ministerie van Verkeer en Waterstaat, Den Haag

Marshall, J.D. and Toffel, M.W., 2005. Framing the Elusive Concept of Sustainability: A Sustainability Hierarchy. Environmental Science \& Technology 39 (3), 673-682

May, A.D., Jopson, A.F. and Matthews, B., 2003. Research challenges in urban transport policy. Transport Policy 10 (3), 157-164

McKinnon, A.C., Ge, Y. and Leuchars, D., 2003. Analysis of Transport Efficiency in the UK Food Supply Chain. Logistics Research Centre Heriot-Watt University, Edinburgh

Meredith, J., 1998. Building operations management theory through case and field research. Journal of Operations Management 16 (4), 441-454

Munuzuri, J., Larraneta, J., Onieva, L. and Cortes, P., 2005. Solutions applicable by local administrations for urban logistics improvement. Cities 22 (1), 15-28

NERA, 2000. Report on Lorry Track and Environmental Costs. National Economic Research Associates, AEA Technology and The Transport Research Laboratory, London

Nicolas, J.P., Pocheta, P. and Poimboeuf, H., 2003. Towards sustainable mobility indicators: application to the Lyons conurbation. Transport Policy 10 (3), 197-208

OECD, 2003. Delivering the goods - 21st century challenges to urban goods transport. OECD working group on urban freight logistics, Paris

Ogden, K.W., 1992. Urban Goods Movement: A Guide to Policy and Planning. Ashgate, Aldershot

Paché, G., 1998. Retail logistics in France: The coming of vertical disintegration. International Journal of Logistics Management 9 (1), 85-93

PSD, 2001. Voorstel regionale afstemming venstertijden. Platform Stedelijke Distributie, Den Haag

PSD, 2002. Van B naar A. Platform Stedelijke Distributie, Den Haag

Randall, T.R., Morgan, R.M. and Morton, A.R., 2003. Efficient versus Responsive Supply Chain Choice: An Empirical Examination of Influential Factors. Journal of Product Innovation Management 20 (6), 430-443

Razzaque, M.A. and Sheng, C.C., 1998. Outsourcing of logistics functions: a literature survey. International Journal of Physical Distribution \& Logistics Management 28 (2), 89-107

Regan, A.C. and Golob, T.F., 2005. Trucking industry demand for urban shared use freight terminals. Transportation 32 (1), 23-36

Richardson, B.C., 2005. Sustainable transport: analysis frameworks. Journal of Transport Geography 13 (1), 29-39

Stock, J.R. and Lambert, D.M., 2001. Strategic Logistics Management. McGraw-Hill, New York

Taniguchi, E. and Van Der Heijden, R.E.C.M., 2000. An evaluation methodology for city logistics. Transport Reviews 20 (1), 65-90

Van Goor, A.R., Ploos van Amstel, M.J. and Ploos van Amstel, W., 2003. European distribution and supply chain logistics. Stenfert Kroese, Groningen

Voss, C., Tsikriktsis, N. and Frohlich, M., 2002. Case research in operations management. International Journal of Operations and Production Management 22 (2), 195-219

Waller, A.G., 1995. Computer systems for distribution planning. International Journal of Physical Distribution \& Logistics Management 25 (4), 35-45

Yin, R.K., 2003. Case study research; design and methods. SAGE Publications, Thousand Oaks 


\section{Publications in the Report Series Research* in Management}

\section{ERIM Research Program: "Business Processes, Logistics and Information Systems"}

2005

On The Design Of Artificial Stock Markets

Katalin Boer, Arie De Bruin and Uzay Kaymak

ERS-2005-001-LIS

http://hdl.handle.net/1765/1882

Knowledge sharing in an Emerging Network of Practice: The Role of a Knowledge Portal

Peter van Baalen, Jacqueline Bloemhof-Ruwaard, Eric van Heck

ERS-2005-003-LIS

$\underline{\text { http://hdl.handle.net/1765/1906 }}$

A note on the paper Fractional Programming with convex quadratic forms and functions by H.P.Benson J.B.G.Frenk

ERS-2005-004-LIS

$\underline{\text { http://hdl.handle.net/1765/1928 }}$

A note on the dual of an unconstrained (generalized) geometric programming problem

J.B.G.Frenk and G.J.Still

ERS-2005-006-LIS

http://hdl.handle.net/1765/1927

Privacy Metrics And Boundaries

L-F Pau

ERS-2005-013-LIS

http://hdl.handle.net/1765/1935

Privacy Management Contracts And Economics, Using Service Level Agreements (Sla)

L-F Pau

ERS-2005-014-LIS

http://hdl.handle.net/1765/1938

A Modular Agent-Based Environment for Studying Stock Markets

Katalin Boer, Uzay Kaymak and Arie de Bruin

ERS-2005-017-LIS

http://hdl.handle.net/1765/1929

Lagrangian duality, cone convexlike functions

J.B.G. Frenk and G. Kassay

ERS-2005-019-LIS

http://hdl.handle.net/1765/1931

Operations Research in Passenger Railway Transportation

Dennis Huisman, Leo G. Kroon, Ramon M. Lentink and Michiel J.C.M. Vromans

ERS-2005-023-LIS

http://hdl.handle.net/1765/2012

Agent Technology Supports Inter-Organizational Planning in the Port

Hans Moonen, Bastiaan van de Rakt, lan Miller, Jo van Nunen and Jos van Hillegersberg

ERS-2005-027-LIS

http://hdl.handle.net/1765/6636 
Faculty Retention factors at European Business Schools

Lars Moratis, Peter van Baalen, Linda Teunter and Paul Verhaegen

ERS-2005-028-LIS

http://hdl.handle.net/1765/6559

Determining Number of Zones in a Pick-and-pack Orderpicking System

Tho Le-Duc and Rene de Koster

ERS-2005-029-LIS

http://hdl.handle.net/1765/6555

Integration of Environmental Management and SCM

Jacqueline Bloemhof and Jo van Nunen

ERS-2005-030-LIS

http://hdl.handle.net/1765/6556

On Noncooperative Games and Minimax Theory

J.B.G. Frenk and G.Kassay

ERS-2005-036-LIS

http://hdl.handle.net/1765/6558

Optimal Storage Rack Design for a 3-dimensional Compact AS/RS

Tho Le-Duc and René B.M. de Koster

ERS-2005-041-LIS

http://hdl.handle.net/1765/6730

Strategies for Dealing with Drift During Implementation of ERP Systems

P.C. van Fenema and P.J. van Baalen

ERS-2005-043-LIS

http://hdl.handle.net/1765/6769

Modeling Industrial Lot Sizing Problems: A Review

Raf Jans and Zeger Degraeve

ERS-2005-049-LIS

http://hdl.handle.net/1765/6912

Cyclic Railway Timetabling: a Stochastic Optimization Approach

Leo G. Kroon, Rommert Dekker and Michiel J.C.M. Vromans

ERS-2005-051-LIS

http://hdl.handle.net/1765/6957

Linear Parametric Sensitivity Analysis of the Constraint Coefficient Matrix in Linear Programs

Rob A. Zuidwijk

ERS-2005-055-LIS

http://hdl.handle.net/1765/6991

Diffusion of Mobile Phones in China

Sunanda Sangwan and Louis-Francois Pau

ERS-2005-056-LIS

http://hdl.handle.net/1765/6989

An Elementary Proof of the Fritz-John and Karush-Kuhn-Tucker Conditions in Nonlinear Programming S.I. Birbil, J. B. G. Frenk and G. J. Still

ERS-2005-057-LIS

http://hdl.handle.net/1765/6992

General model for automated diagnosis of business performance

Emiel Caron and Hennie Daniels

ERS-2005-058-LIS

http://hdl.handle.net/1765/6987 
Exploring retailers' sensitivity to local sustainability policies

H.J. Quak and M.B.M. de Koster

ERS-2005-066-LIS

* A complete overview of the ERIM Report Series Research in Management: https://ep.eur.nl/handle/1765/1

ERIM Research Programs:

LIS Business Processes, Logistics and Information Systems

ORG Organizing for Performance

MKT Marketing

F\&A Finance and Accounting

STR Strategy and Entrepreneurship 